R. Listórlo, Sĩo Paulu, n. 129-131, p. 165-178, ago.-dez./93 a ago.-dez./94

\title{
RACISMO NO SUL DO BRASIL: HERANÇAS DE UM MITO
}

\author{
Marionilde Dias Brepoll de Magallı̄es *
}

RESUMO: Este estudo tem por objetivo disculir alguns aspectos do pangermanismo no sal do Brasil analisadu sobre o prisma da cultura e suas imbricaçies com o racismo. Etnia e iufioma, usos o costumes se apresentam como eiementos identificadores e necessírius aos estuchos sobre a diversidade histórica. A partij da reconstiluiçio das ativjdades da Liga Pnngermânica na América Latina e, especificamente, no Brasil, a autora analisa o revigoramento de uma consciencia pairiótica e nacionalista por mate dus imigmntes germánicos. Apoinnub-se eln documentos produzidus apus a I Guerm Mundial, constata e analisa a manifestaçâo cle novas atitudes por parte dus descendentes dos ieutos. $A$ construçto mflica do passacu hercitico germânico é um dư itens em questĩo.

PALAVRAS-CIIAVE: imigraş̊ô, teutos, assimilaçåo, resistêncin, pangermanismo.

\section{Introduçäo}

Qualyuer historiador que analise os periódicos, folhetos, estórias e conlos em língua alemã, edilados no século XIX no sul do Brasil, surpreende-se com a diversidade de gostos, gêneros, lendências políticas e literárias.

Contudo, uma questão thes é comum: a memória da imigração. $O$ ato de nigrar, as perdas que implicam tal opção e a euforia face a seu novo mundo sâo discursos recorrentes.

A partir do final do século XIX, entretanto, essa pluralidade cederá a um discurso homogeneizador, em que a ideologia racial (o mito ariano) ocupa um lugar destacado. O entusiasmo com a unificação da Alemanha em 1870, a experiência da derrota na primeira guerra e, finalmente, o movimento nacional-socialista sāo episódios que afetam boa parte dos emigrados, como se aquela história thes pertencesse.

Quem são estes indivíduos? Trata-se de um segmento da segunda ou lerceira geração dos imigrantes pioneiros, que saíram, com o tempo, do meio rural e se afirmaram na cidade como pequenos e médios comerciantes, donos de fábricas ou arlesãos, passando portanto por um processo de ascensão

- Doutoranda en llistória pela UNIC:AMP. Professora da Universidade Federal do Parana. 
MAGALHĀES, Marionilde Dias Brepohl de. Racismo no sul do Brasil: herangas de um mito.

economica e social. Pequeno-burgueses, ávidos por ascensño de statts, ressentidos com os preconceitos das eliles dominantes no Brasil contra o gringo, o alemão batata, o estrangeiro, vislos como pessons sem um lugar nesta história. E, para compensarem este déficit de statıs, 1ais indivíduos acercamse do pangermanismo, um sentimento de identidade que cra nutrido, em boa medida, pelas doutrinas raciais então existentes.

Discutir alguns dos aspectos desta cultura e suas relaçóes como racismo, ainda que nāo velado, no sul do Brasil, é o objetivo deste Irabalho.

\section{De imignantes a "alemães"}

Em inúmeros impressos de língua alemã que circulavam no Brasil de 1890 a 1945, observamos um tralamento homogeneizador para os descendentes de origem germânica na América Lälina. Enunciados como Deutschıım (germanidade), alemães, povos de uma outra nação que não aquela onde habilavam, herdeiros de uma pálria uuificada, são tcrmos que operam um distanciamento em relaçĩo à sociedade receplora.

Ainda que muitas famflias já eslivessem instaladas no Brasil há mais de 80 anos, e outras nāo fossem sequer descendentes de alemães, mas de suíços, austríacos ou russos, pouco importava: elnia e idioma, usos e coslumes eram seus elementos identificadores, para o que a diversidade histórica de suas origens (logo, as diferenles memórias), devia ser apagada.

Quais os fatores responsáveis por esta mudança de linguagem?

A partir de 1870, a reunificação alemã autoriza alguns empresários e políticos a entenderem quaisquer teutos como cidadäos do Reich. Tal conceito se deve principalmente a uma cntidade, qual seja, a Liga Pangermanica. Sua história está vinculada à expansảo imperialista européia, que passou a disputar, no final do século XIX, novos e mais diversificados mercados em vários países, substituindo as lálicas de conquisla lerritorial pela concorrência inter-capitalista e pela propaganda política e cultural. Tal foi o procedimento das classes dominantes alemás, se bem que revestido de algumas especificidades, das quais se destacam pelo menos duas:

- a cooperação técnica, científica e militar, desenvolvida por missóes diplomáticas que visavam, em médio prazo, atrair a atenção das cliles latinoamericanas para as suas mercadorias;

- o investimento maciço de maleriais de propaganda sobre a superioridade do povo alemão, sua cullura, raça e economia, impressos que eram veiculados exclusivamente entre os imigrantes e seus descendentes desta origem; em médio prazo, estes entusiastas nacionalistas sonhavam em criar 
nas regiốes de colonização alemã do cone sul uma república teuta, separada inslitucional ou culturalmente dos países em que se situavam, e diretamente vinculada aos interesses da naçĩo alemã. Para tanto, estes empresários, jornalistas, comerciantes e pastores ligados ao prolestantismo nacionalista, liveram de enfrentar as resistências de Bismark, para quem, em suas estratégias expansionistas, não estava conlemplada a conquisla territorial, e, muito menos, qualquer inlerferéncia que pudesse afetar suas boas relaçōes com os Estados Unidos, a economia líder do Novo Mundo. Bismark considerava ainda dispendioso o investimento bélico necessário à conquista territorial de ultra-mar c à montagem de uma burocracia que the garantisse a dominação na região ocupada, motivo pelo qual lais prálicas foram preteridas em favor do livre comércio, dadas as vantagens comparativas das mercadorias alemãs.

Esla posição oficial não impediu que empresários ligados à ideologia imperialisla deixassem de sonhar e militar em favor de suas utopias de expansão territorial, o que seria incorporado mais larde ao nazismo sob a justificativa de necessidade de ampliaçāo do espaço vilal (Lebensraum). Tais grupos iniciaram, de maneira aulônoma $\mathrm{em}$ relação ao Estado, uma série de investimentos nos países de América Latina, inspirados não apenas num espírilo pragmálico que lhes garantisse o lucro, mas lambém por um senso missionário e expansionista, caraclerístico dos imperialismos, bem como por uma espécie de nacionalismo de caráter tribal, que buscava agregar todos os membros de uma mesma etnia em torno de um poder central, legitimado pela noção românlica e conservadora de identidade nacional.

A partir de 1890, no governo de Caprivi, que substitui o de Bismark, os idealizadores do expansionismo alemão passarão a contar com o apoio institucional, o que fortalece sua posição em mercados como os do Chile, Peru, Argentina, Paraguai e Brasil. Além da expansão comercial, ressalte-se sua influência na formação dos exércitos chileno e argentino, a dispula por colônias na frica, a discussăo parlamentar e extra-parlamentar sobre fronteiras alemãs na própria Europa, dentre outras reivindicações. No Brasil, os agentes do imperialismo alemão dedicavam-se especialmente às exportaçóes e imporlações de mercadorias e à doutrinação pangermanista entre as colonias onde o número de imigrantes alemãcs e de seus descendentes fosse expressivo.

Neste tocante, merece deslaque a posição de Karl Peters, um líder político que foi diretor de algumas colónias na frica, onde não hesitou em empregar quaisquer mélodos de violência para impor o poderio militar alemão. Mas, no que se referia ao Brasil. Karl Peters dispensou um outro Iratamento. Considerava imprescindível apoiar seus camaradas de etnia (Volksgenossen), opondo-se à doutrina Monroe, pois avaliava que a América 
MAGAlHĀES, Marionilde Dias Brepohl Je. Racismo no sul do Brasil: herangas de um mito.

Latina era, sob o ponto de vista cultural, mais distinta dos Estados Unidos do que da Europa; o panamericanismo era por ele considerado um artifício ideológico para interferir nos negócios de outros países, logo, uma ameaça à sua soberania.

Sun concepção de nação era bem simples de ser entendida, se bem yue pouco aceitável segundo as tradiçōes do bloco ocidental. A identidade nacional era concebida pelo crilério de raça c idioma, ao que se ajustou a noção de superioridade étnica, válida somente pará os arianos puros, e não para qualquer tipo de branco. Sua finalidade úllima passou a ser vencer o inimigo, fossem oulras naçöes, como a França, a Inglalerra e a Russsia, oulros povos, como os judeus, ciganos e eslavos ou outras idcias, como o liberalismo e o socialismo (SNYDER, 1984).

O movimento, antes e depois de se organizar, teve mais simpalizantes do que adeptos. Fascinava as classes méclias por sua xenofobia e por alimenlạr-lhes o sentimento de ameaça, mas causava-lhes temor por sua avidez pelo poder político. (Afinal, o pequeno-burgues nunca considera a polílica uma linguagem com a qual ele podia ler interlocutores). O pangermanismo se desenvolveu primeiramente na uslria, a partir de 1860, caracterizando-se pela sua franca oposição ao governo, facc às suas pos/uras liberais. Seus idealizadores elegeram Bismark seu líder (posiçāo que não dependeu de seu empenho ou desejo pessoal) e catalizou o descontentamento da pequena burguesia, assustada com o risco de secessão que o sionismo, também cmergente, se lhes representava. Suas lideranças foram responsáveis, por se Jefinirem como arautos de uma nova cultura polfica onde o poder e a responsabilidade se integravam de forma diversa da cultura de liberalismo racional'. Destes personagens, o mais destacado foi Schönerer, por sislematizar as idéias ligadas ao anli-semitismo e por suá habilidade em arlicular uma militancia extra-parlamentar, posiçōes que inspiraram sobremaneira seu discípulo mais conhecido, Adolf Hiller.

O pangermanismo dos austríacos, forma de nacionalismo $\mathrm{cm}$ nível macro, que distintamente dos demais não pressupunha a reunião de diferentes etnias, como o pan-eslavismo na Rússia, desenvolve-se lambém na Alemanha, onde o movimento se organiza com ambições políticas mais definidas a partir da década de $\mathbf{9 0}$ do século XIX, com a criação da Liga Pangermânica - Alldeusschen Verband. Esıa entidade atraiu nacionalistas de todos os matizes, fossem intelectuais, como Max Weber, Haeckel e Theodor Fischer, ou militantes, como Hugenberg, Haase e Class, que se apoiavam em idéias dos

1 Sobre as origens do pangermanismo austríaco, ver: SCIIORSKE, 1988. 
R. Ilistórla, São Paulo, n. 129.131, p. 165-178, ago.-dez./93 a ago.-dez./94.

românticos do início do século, associando-as à ideologia do nacionalismo estatal/oficial. Contavam ainda com o apoio de outras entidades, das quais é importante destacar a Deutsche Kolonialgesellschaft - Socicdade Colonial alemã e a Verein fïr das Deutschtum im Ausland - Liga pela Germanidade no Exterior (VDA). Alguns partidos nacionalistas, como o Deutsche Nationale Volkspartei - Parlido Popular Nacional - emprestaram-lhe seu apoio, lutando para aprovar diversas medidas de seu interesse no parlamento. Seus principais objetivos, expressos em seus estatulos eram:

"- Divulgação e propagação dos planos expansionistas da germanidade;

- Luta pelo forlalecimento da frota naval;

- Uniño integral da germanidade em todo o mundo;

- Campanha em favor da germanidade no exterior;

- Luta contra as minorias nacionais" ${ }^{2}$.

No século $\mathrm{XX}$, a estes objetivos somam-se ainda a exigência de se estender os direitos de cidadania aos alemāes do exterior, sob argumentos baseados no princípio do jus sangïinis. Coerentemente, recusavam a concessão de cidadania aos indivíduos de outras eınias residentes no país. Reforçavam ainda sua postura anti-semita e estimularam propagandas favoráveis ao conflito armado.

Suas idéias foram divulgadas rapidamente nos perfoclos em língua alemã do Brasil. A atuaçăo da VDA se destacou também pẹ̣a sua dedicação ao ensino fundamental; ao prestar auxílio às escolas particulares de língua alemã, ela preparava as crianças e jovens para o pangermanismo do futuro. Financiava sua construção, doava equipamentos, livros didáticos e enviava alguns docentes formados na Alemanha para inlegrarem seus quadros. Sob o le ma Gedenke dass du ein Deutscher bist - "Lembra-le que tu és um alemāo", patrocinava ainda viagens de estudos para os melhores alunos. Esse slogan (para empregarmos um termo contemporâneo) era impresso nos cadernos, livros, almanaques, calendários, elc, como que, pela força da repetição, fosse introjetado no público receptor uma "culpa preventiva": a do esquecimento.

Ao lado do material didático e das inúmeras contribuiçōes nos periódicos, quer sob a forma de artigos, quer pelo auxílio financeiro, os quais se incumbiram pela formação de uma determinada mentalidade, de 1890 até pelo menos 1916 , cite-se ainda a criaçāo da Zentralstelle für die Forsc/mung des Deutschtıtms 
MAGALHÃES, MarionitJe Dias Brepohl de. Racismo no sul to Brasil: heranģas Je um mito.

im Ausland - Central de Pesquisa da Germanidade no Exterior - (ZDA), órgão que subsidiará os programas de pesquisa que apóiam a emigração c o fomento a cultura pangermânica, esta, IransLormada $\mathrm{cm}$ uma nova ciência (como se ciencia, ou qualquer oulro saber, pudesse ter uma pátria específica. Consideramos que o saber, quando efelivamente válido, é necessariamente universal). Os membros da ZDA preparavam estudos sobre a polftica latinoamericana, as regiōes mais propícias para a inslalação de emigrantes e fornecia ainda subsídios para os pangermanislas residentes nestes países. Entendiam ser sua tarefa precípua a formação de uma elite que garantisse a preservação cultural de lodos os descendentes teutos. Segundo Kuder, um membro desta instituição, a preservação do Deutschurım por meio da literatura era uma tarefa da comunidade nacional alemã. Tais pesquisas e livros eram igualmente veiculados entre a população teuta, sendo cuidadosamente cscolhidos para este fim. No campo religioso, tornou-se linguagem corrente a afirmativa: Luthertum ist Dettschumm (Luteranismo é germanidade).

As atividades da Liga Pangermanica e de seus adeptos na América Latina sofrem um impulso decisivo com o advento da primeira guerra mundial. Com ela, verifica-se um despertar da consciência patriótica e nacionalista por parte dos imigrantes e de seus descendentes, fomentado, em boa medida, por ayuelas organizaçōes, mas lambém (e não num segundo plano), pelas tensóes ocorridas entre os membros daquela elnia contra a sociedade receptora. No Brasil, tais tensōes sāo extremamente agudas, nāo apenas pelo fato de serem suas elites mais fiéis ao panamericanismo do que as dos outros dois países da América Lalina, em virlude de seus laços economicos com os Estados Unidos, mas lambém pelo comporlamento adolado face àquele conGlito. Quando, em 5 de abril de 1917, o mercante "Parantá" é bombardeado na costa francesa pelas belonaves do Reich, o governo brasileiro rompe relaçóes diplomáticas com a Alemanha, para em oulubro, devido às sucessivas pressôes dos aliados e da Liga da Defesa Nacional, declarar guerra à Alemanha. A partir dá, as agressōes e manifestaçóes de repúdio aos descendentes germanicos (quaisquer que fossem) se ampliam, passancio os tculo-brasileiros a serem considerados como inimigos e estrangeiros. A divulgação do milo do "perigo alemāo" adquire um espaço cada vez mais destacado na imprensa de lóngua porluguesa: o "fanlasma" da anexação do sul no caso da derrota dos aliados insligam a indignação dos mais diversos segmentos sociais, que passam da aversāo ao ódio pela figura do alemão, enxergando nele, uma inclinação hereditária à agressividade. Estas imagens favorecem uma onda de quebra-quebras, comícios e empastelamentos de jornáis, atos oriundos, notem bem, da sociedade civil, e não do Estado, como aqueles que ocorrem na era Vargas. Em 1917, é a sociedade receptora yersus a comunidade teuta 
R. Histórla, São Paulo, o. 129-131, p. 165-178, ago.-dez./93 a ago.-dez./94.

quem entra em guerra; de ambos os lados, uma postura beligerante, como se estivessem residindo na Europa, não no Brasil.

Esta experiência resultará, com o término da guerra, numa cissura entre aquelas camadas e a sociedade receptora, o que se faz acompanhar por um refluxo das propostas de integraçāo e assimilação de ambos os segmentos sociais. A partir daí, na linguagem jornalística, observa-se que os teutos passam a se expressarem como vilipendiados em seus direitos, tăo derrotados quanto seus compatriotas da Alemanha, e passam a ansiar, em suas elaborações limite, por uma nova remigração.

\section{O pangermanismo no perfodo entre-guerras}

Esta é uma conjuntura em que se caracteriza um momento-limite da história dos descendentes dos teutos. Face às discriminaçōes que sofreram, sua atitude interior foi a de desforra, indignação e distanciamento da comunidade receptora. Isso pode ser observado inclusive em suas atitudes cotidianas. Em boa parte de seus escritos, constata-se que o passado é eleito como alternativa. A memória de seus ascendentes é reorientada; lembram-se menos de suas conquistas e mais de seus sofrimentos. Recordam-se que o Brasil não lhes deu boa acolhida, esquecendo-se, ao mesmo tempo que foi neste país, que seus pais deixaram se ser servos e passaram à condiçāo de proprietários.

Nos periódicos em língua alemã que sobreviveram aos empastelamentos ${ }^{3}$, constata-se que, logo após o término da primeira guerra mundial, há um certo arrefecimento no que se refere à afirmação do Deutschtum e de seu posicionamento face à esfera pública local. Mas, tão logo seus jornalistas e colaboradores se sentissem seguros para manifestarem suas conclusōes sobre os conflitos decorrentes da guerra, passaram a refletir uma série de atiludes hostis face à sociedade que os circunscrevia. Cite-se, a exemplo, um editorial que considera que,

a situação política está mais tranqüila, mas que a "flâmula vermelha" e a propaganda anti-germanista dos aliados ainda subsistem, instigando os habitantes de diversos países contra os teutos; o odio generalizado que todos

Ressalte-se que os que puderam se reorgnaizar foram aqueles, cujas entidades patrocinadoras tinham maior poder aquisitivo, ou $\alpha$ que receberam auxflios do Reich. As não se inclui obviamente as pequenas grificas, muito menos aquelas que eram manticas por movimentos social-democratas, socialistns ou anarquistas. 
MAGALHĀES, Marionilde Dias Brepohl de. Racismo no sul tu Brasil: beranģas de um mito.

sentem por eles, deve lines ser um molivo de orgulho, pois tal atitude reflete o reconhecimento de ser o povo germanico uma comunidade étuica (Volksgemeinschaft), sulidária e unida, independentemente dos estados a que perlença (KDB 1918, 1921 e 1922).

Ou seja, a geografia imaginária desles escrilores (e de muitos leilores), transforma-se: eles, em alguns momentos, parecem residir na Alemanha, não no Brasil.

Um outro indício deslas alitudes defensivas e a criaçāo, em 1919, da Deutschen Schutzbund fiir die Grenz - "und Auslandsdeutschen, uma federação que reunia diversas organizaçōes para a proteçāo dos alemães residentes em regiōes fronteiriças e no exterior, uma inicialiva Ja VDA, que contou con recursos do governo alemão para auxiliar seus compatriolas da América Latina prejudicados com o advento da guerra.

Entretanto, se o número de periódicos, associaçōes e entidades cullurais se ampliam; o conteúdo de suas mensagens são cada vez mais homogeneizados, em torno de algumas questōes fundamentais: a necessidade de preservação do idioma de origem, o afastamento deliberado da polílica, a nộāo de superioridade étnica e cultural. Ainda, uma idealização da nação alemã para além dos acontecimentos políticos a ela pertinentes, manifestando um determinado desejo (consciente ou não) de reslauração hn honra perdida. Assim, a literatura, a música ou a história são comemoradas como os efelivos emblemas de sua pátria. Ilustra este imaginário, o excerto do seguinte poema:

O que significa a tua língua malerna,

Que a ti lua mãe ofereceu?

Já te colocaste esia difícil pergunta

Em tuas horas solitírias?

Tenta, pois, dizer numa língua esıranha,

O que vai em teu coração

Só a língua mãe, que chora,

Pode alcançar o que leu peito alcança

(Kalender fïr die Detuschen in Brasilien, 1907, p. 42)

Ou, de forma mais pedagógica, recomenda um pastor protesıante,

Como cada família tem suas virtudes e defeitos, assim $\boldsymbol{\varepsilon}$ um povo; cada um lem sua elnia, e é melhor para todos que eles se maılenham assim divididos.

(Kalender für die Deulschen in Brasilien, 1923, p. 17-35). 
R. HIstórta, São Paulo, n. 129-131, p. 165-178, ago.-dez./93 a ago.-dez./94.

Com esta linguagem passional, semi-religiosa, contrapōe-se o jus soli, vigente nas Américas, ao jus sangüinis, de sua própria tradição, em nome do que seus precursores iniciam uma polémica que só será concluída com a segunda guerra mundial. Este princípio thes permite conceber a sociedade em que vivem como dividida entre várias etnias, logo, várias nacionalidades. Neste debate, a população majoritária da sociedade receplora é por eles denominada de "luso-brasileira", o que nāo apenas exclui as demais, mas enuncia seu caráter histórico de camada dominante. Caracterizam os membros deste grupo como seus principais adversários, desqualificando-os, conforme o caso, como vadios, inclinados à miscigenação, latifundiários, corruplos e escravocratas. Em relação aos outros demais, reconhecem o direito à manutenção de sua cultura, desde que não se misturem entre si.

Dentre todos os povos ou etnias que mencionam, a única que não deve ler o direito à existência nos países do ocidente $e$, sègundo os pangermanistas, a judia. Trata-se de um povo errante e apatrida, que deve retornar ao oriente, pois suns raízes e sua cultura não se harmonizam com o espírito idealista alemão ${ }^{4}$.

No geral, estes escritores reforçam suas recomendaçōes no que se refere à organização da comunidade teuto-brasileira de maneira corporativa e autónoma dos países em que vivem. Quando se expressam sobre a vida pública, não o fazem para fomentar uma determinada forma de açāo coletiva, mas como um argumento adicional que favorecesse seu auto-enclausuramento.

Esta atjlude de resignação não pode ser compreendida apenas como um resultado dos conflitos ocorridos em virtude da primeira guerra, ou de suas próprias experiências com a política interna. Ela é também resultado da emergência de uma linguagem de natureza totalitária, a qual já se presenciava na Europa desde o final do século XIX, com elaborações que refletiam o ocaso das ulopias liberais e o celicismo com relação à democracia. Mas é no infecio do século XX, quando os conteúdos utópicos da sociedade do trabalho ameaçam ser colocados em questão pelos movimentos revolucionários, que o pensamento iluminista começa a perder sua relevancia política. Neste momenlo, o Romantismo fin de siecle, a psicologia das multidóes, as doutrinas raciais, são recorrentes entre teutos e mesmo entre os demais habitantes do Brasil, o que encontra uma razoável receptividade principalmente entre as classes médias. Neste momento, os apóstolos da nação recorrerão a passados exemplares nos quais o presente pudesse confiantemente se orientar.

BREPOHL, F.W. Mein Kampft in der deutschbrasilianischen Presse gegen judischen Misbrmuch des Auslanddeutschen Idealismus im Jalire 1931. Ponta Grossa: Verlag der Deutschen Vereinjgung für Evangelisation und Volksmission, 1931. $38 \mathrm{~S}$. 
MAGALHÃES, Marionilde Dias Brepohl de: Racismo no sul do Brasil: heranças de um mito.

A elaboração mílica do passado heróico germanico, reitera continuamente, possibilita que tudo seja germanizado; Detuschumm torna-se um conceito chave, que se apóia mais num sentimento. do que numa proposta formulada no campo racional; aos homens não cabe a vontade ou qualquer juízo face à esfera pública, pois são formados por uma mesma natureza, o que, em seus limites, aniquila inclusive a hipótese mesma da necessidade do debate, do conflito, vale dizer, da política. São, a um só tempo, membros de um mesmo corpo, e individualmente, corpo integral que reflete todo o conjunto desta comunidade (Volksgemeinschaft).

Era portanto previsível que diante de tal experiencia, os teutos se aproximassem ainda mais de sua cultura original, afastando-se, conseqüentemente, das propostas de integraçāo à cultura receptora. Mas além desta đisposição deliberada de resistencia à assimilação, tais sentimentos serão estimulados por novos (ou rejuvenescidos) agentes do imperialismo cultural alemão, os quais ganham uma coloração mais nítida com o advento do nacional-socialis mo.

Com a ascensão de Hitler, alguns periódicos alemães irão afirmar que,

enquanto na democracia o estado não era senão um instrumento cas classes sociais, com o nacional-socialismo, é o povo quem assume o estado e o coloca a seu serviço". A vitória de Hiller é anunciada também como o "triunfo da vontade de um povo sob a liderança do Fillhrer, e que a partir de agora, tudo o que lá em cima ocorrer, será sinonimo desta vonlade (Kalender für die Deutschen in Brasilien, 1934, p. 13 e, Koserilz' Volkskalender, 1934, p. 97-98).

A partir desta conjuntura, as entidades pangermanicas passarão a ser disputadas e influenciadas por uma nova organização, qual seja a Auslandsorganization - A.O. (Organização para o Exlerior do NSDAP), sob a liderança de Bohle, um membro do segundo escalão do partido, que objetivava conquistar a fidelidade dos alemães do exterior, fosse para transformá-los em representantes dos interesses econômicos do Reich, fosse para formar uma reserva militar a ser recrutada em caso de conflito armado. Para tanto, investiu pesadamente num conjunto de estratégias de propaganda, que ia desde a promoção de eventos culturais até a formação de células nazistas em cada uma das regióes de colonização da América Latina. Segundo ele, para que todos se tornassem alemães integrais, era imprescindível que se transformassem em nazistas integrais ${ }^{5}$.

5 Correspondència confidencial ta A.O., 1937. Arguivo de Ilistoria Conlemporínen, Munique. 
R. História, São Paulo, n. 129-131, p. 165-178, ago.-dez./93 a ago.-dez./94.

Ao observarmos as formas de estruturação desı propaganda, conslatamos que sua lógica se baseou na necessidade de irradiação de um conjunto de idéias-força que visava recobrir todo o campo cultural que se pretendia dominar. $O$ caráter escatológico que ela passou a assumir foi favorecido pelo distanciamento a que estavam sujeitos seu público alvo de todos os eventos relativos ao governo de Hitler. Is to cooperou para que o regime fosse idealizado como uma alternativa salvadora diante das "perseguiçōes" que passam a ser realizadas pelos mais diversos órgāos da política institucional dos países em que residiam. face a esia dupla pressăo, ou seja, da propaganda do NSDAP e da contra-propaganda dos poderes oficiais, eles passaram a se afastar ainda mais de quaisquer membros da sociedade receptora.

Tornaram-se apáticos, no que se referia à política brasileira ${ }^{6}$; mas, em suas associaçōes e entidades recreativas, bem como em artigos e jornais, observa-se uma tendéncia que associava a idéia de auto-enclausuramento com fortalecimento político, como se se tratasse de um corpo que deveria crescer para depois enfrentar os demais. Para tanto, tornava-se imprescindível a coesão interna, o que implicava, simultaneamente, na endogamia. Como, a exemplo, manifesta-se o seguinte trecho de um editorial:

Somos um milhāo de alemāes no Brasil. Somos um exército sem soldados, uma Igreja sem torre, aceitai o desafio agora... - Vós fostes chamados para serem líderes deste povo, pois sois o povo, mais inteligente deste terra. (Kalender für die Deutschen in Brasilien, 1933).

Este comportamento, como é sabido, sofreria inúmeras interdições por parte da polícia política de Vargas, após a adesão do governo brasileiro às tropas aliadas. $O$ "sonho" de se viver em "pequenas ilhas arianas" se esvairia com a chamada campanha de nacionalização. Com ela, prenderam-se ou baniram-se líderes do NSDAP, pargermanistas e mesmo descendentes de alemães que não participaram de tal movimento. Simultaneamente, proibiuse a exisıência de associações e impressos. bem como o emprego do idioma alemão. Pesaria ainda contra este grupo, a imagem de nazistas, quinta-colunas e assassinos, o que se verifica, em muitos casos, até os dias atuais.

6 Goslarfamos de ressaltar que, nem todos os mngermanistns distanciaram-se dn politica. Alguns deles, notndamente os intelectuais, exerceram influência sobre as politicas oficiais orientadas por nogúes eugenistas da era Vargas. Ver: BREPOHL de MAGALHAES, 1993, p 72 e ss.). 
MAGALlIÄES, Marionilue Dias Brepohl de. Racismo no sul do Brasil: heranģas de um mito.

\section{Consideraçöes finais}

Não estudamos, senāo por meio da literalura e de algumas obras de cientistas sociais, o período posterior à Segunda Guerra Mundial. Mas algumas consideraçōes podem ser formuladas.

Um falo que nos chama a atenção, é que não voltou a publicar periódicos em língua alemā. Tampouco suas associaçōes, excelo algumas, voltaram a ser denominadas com palavras ou nomes próprios neste idioma.

No que concerne aos descendentes da geraçio que conviveu com a Segunda Guerra, dois comportamenlos podem ser observados podem ser observados: a rápida assimilaçāo à cultura dominante ou, um retorno à narrativas ligadas aos imigrantes pioneiros. Em ambos os casos, constala-se um silencio sobre os anos imedialamente precedentes?

Mas, se atentarmos para a reflexöes Je Michạel Pollak (1989), sobre a função do não dito nas elaboraçōes de uma determinada memória coletiva, poderemos formular, pelo menos, algumas hipóteses interessantes. Para o autor, à medida em que um determinado grupo silencia sobre seus atos, seja por culpa, vergonha on ressentimento, de forma alguma clé os esquece. Pelo contrário, as lembranças proibidas sĩo guardadas e mantidas em estrutura de comunicação informais, como a lamília, enıre amigos, cm ocásiōes festivas. São metáforas, alusões, entreolhares c sorrisos, os quais substituem um discurso interior que não quer (ou não pode) revelar-se.

No que se refere ao Paraná c Sanla Catarina, por exemplo, encontraremos algumas alteraçōes nas auto-nomeaçōes de alguns desies descendentes, que nos parece muito signilicalivas: ao inves de teuto-brasileiros ou germanicos, "filho de colono alemão". Ao invés de branco, "loiro de olhos claros". Ao invés de apreciarem a cultura alemã, [ala-se em "[estas [olclóricas". Ao invés de raça superior, "trabalhadores c ordeiros".

Finalmente, um outro fragmenlo de seu passado que só tem se revelado, de forma mais audível, no período recente; ao invés de Alemanla ou colônias alemās, Região Sul.

No que se refere a cssa úllima operação simbólica, devemos ressaltar que ela não e expressa por descendentes de alemães, mas por um amplo segmento da sociedade sulina, notadamente entre parcelas da classe média,

7 Os iftulos thes trabalhos que reescrevem a histótin da imigragîo alemf no Brasil sîu bastante sugestivos, no que se refere a imagem que se pretende veicular sobre esta camala. Cite-se, pelo

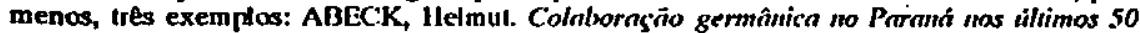
anas; OBERACKER, Karl. Contrilutiçión tenta h nagĩo trrsileirm, MARIINS, Wilson. Um Brasil diferente. 
R. Histórta, São Paulo, n. 129-131, p. 165-178, ago.-dez./93 a ago.-dez./94.

que têm mencionado, em alguns de seus discursos, idéias em favor do separatismo. Af, a associaçāo de origem racial à "força económica (verstus a "preguiça", associada à pobreza do Nordeste brasileiro) parece inspirar-se em um dos postulados da Liga Pangermânica: o direito à cidadania deve ser condicionado à herança racial, à existência de um passado comum, à presença de uma comunidade de sentimentos que, ao reforçar-se, exclui o diferente, tratando-o como estrangeiro.

\section{Bibliografia}

ABECK, Helmut. Colaboração pangermánica no Paraná nos uiltimos cinqüenta anas (1929-1979). Entre Rios, 1980, 150p.

ANDERSEN, Benedict. Nas̆̃o e consciència nacional. Sĩo Paulo: X́ticn, 1989, 191 p.

ARENDT, Hannah. O sistema totalitário. Lisbon: Dom Quixote, 1978, 622p.

. Entre o passado e ofuturo. Sáo Paulo: Perspectivn, 1972.

BRACHER, Karl Dietrich. La dictadura alemana: genesis, estructura y consecuencias del nacional-socialismo. Madri: Alianza, $19732 \mathrm{v}$.

BREPOHL DE MAGALHES, Marionilde Dias. Alcmanha mae pátria distante; utopia pangermanista no sul do Brasil. Campinas, 1993. Tese de Doutorado. Universidade Esladual de Campinas, 320p.

GERTZ, René. O fascismo no sul do Brasil; germanismo, nazismo, integralismo. Porto Alegre: Mercado Aberto, 1987, 204 p.

GlL, José. Naçăo. IN: Enciclopédia: Estado-Guerra. Lisboa: Einaudi: Imprensa Nacional Casa da Moeda, 1989, p. 276-305.

GIRARDET, Rnoul. Mitos e mitologias políticas. Săo Paulo: Companhia das Letras, 1988, $212 p$.

HOBSBAWM, Eric. Naçסes e nacionalismo. Rio de Janeito: Paz e Terra, 1990, 230p.

KOHN, Hans. Dic idee des Nationalismus. Heildelberg, 1950, $318 \mathrm{~s}$.

KRUCK, Alfred. Geschichte des Alldeutschen Verbandes 1890-1939. Wiesebaden: Franz Steiner, 1954, 224s.

LEXICON zur Parteien Geschichte. Köln: Pahl Rugenstein Verlag, 1983, 2 Bånde.

MARTINS, Wilson. Um Brasil diferente. Sāo Paulo, T.A.Queiroz, $2^{\star}$ ediçăo, 1989, 470p.

OBERACKER JR, Carlos. A contribuiçāo teuta d̀ formạ̧ao da naçao brasileira. Rio de Janeiro: Presença, 1968, 579p.

OLIVElRA, Lucia Lippi. A questão nacional na primeira rcptiblica. Săo Paulo: Brasiliense, 1989, 207p.

POLLACK, Michael. Memória, esquecimento silêncio. Estudos Hisłóricos. Rio de Janeiro: v.2, n.3, p. 3-15, 1989.

POLIAKOV, León. O miro ariano. Sāo Paulo: Perspecliva, USP, 1974, 323p.

REICH, Wilhelm. Psicologia de massa do fascismo. Porto: Escorpifo, 1974, 194p. 
MAGALhÃES, Marionilde Dias Brepohl de. Racismo no sul tw Brasil: beranģas de um mito.

SAYRE, Robert \& LOWWY, Michael. Romantismo e polffica. Rio de Janeiro: Paz e 'lerm, $1993,98 p$.

SEYFERTI, Giralda. Nacionalismo e idemidtade émica. Foriạuópolis: Tundaçfio Catarinense de Cultura, 1982, 223p.

SNYDER, Louis. Macro-nationalism: a history of the pan-motrements. Westport, Connecticut: Grewnwoxl l'ress, 1984, 308p.

SCHORSKE, Cart. Viena fin de siecle: políica c culturn. São Paulo: Companhia das Letras, 1988, 373p.

VERISSIMO, Erico. O tempo e o vento. IN: Obras completas (10l. $I I$-V). Rio de Janeiro: José Ayuilar, 1966(b).

ARSTRACT: This study is a tiscussion of some viewpoints lotward Pan-Germanism in southern Brazil and its redation with racism. Ethnos and idiom, uses and custums are elements of indentification and necessary to studies abuut historical diversity. Beginning with a reconstitution of the Pan-Germanic Lengue's activities in Latin America, more specifically in Brazit, the atthor analyzes the strengihening of a patriotic and nacionalistic conscience of German immigmnts. Using doctments dteil after Wortd War I, new attitudes of the Teutonic lescendents are revealed and discussed. The mythical cuastruction of the German hervic past is one of the issues.

KEY-WORDS: immigration, Teuton, assimilntion, resistance, Pan-Germanism. 